This item was submitted to Loughborough's Research Repository by the author.

Items in Figshare are protected by copyright, with all rights reserved, unless otherwise indicated.

\title{
Accidents, injuries and safety priorities for light goods vehicles in Great
} Britain

PLEASE CITE THE PUBLISHED VERSION

PUBLISHER

(C) IMechE / Professional Engineering Education

LICENCE

CC BY-NC-ND 4.0

REPOSITORY RECORD

Lenard, James, Richard Frampton, Alan Kirk, Andrew Morris, R. Newton, Pete Thomas, and Paul Fay. 2019. "Accidents, Injuries and Safety Priorities for Light Goods Vehicles in Great Britain". figshare.

https://hdl.handle.net/2134/1854. 


\title{
Accidents, injuries and safety priorities for light goods vehicles in Great Britain
}

\author{
J Lenard ${ }^{1 *}$, R Frampton ${ }^{1}$, A Kirk ${ }^{1}$, A Morris ${ }^{1}$, R Newton ${ }^{1}$, P Thomas ${ }^{1}$ and P A Fay ${ }^{2}$ \\ ${ }^{1}$ Vehicle Safety Research Centre, Loughborough University, Leicester, UK \\ ${ }^{2}$ Ford Motor Company, Basildon, Essex, UK
}

\begin{abstract}
This study presents data on light goods vehicle (LGV) crashes. The data are derived from two main sources. The first source involves mass analysis of crashes involving LGVs recorded in the national British STATS19 accident database for 1994 to 2000. The second source involves analysis from an in-depth study of LGV accidents in Britain since the late 1980s. In total, in-depth data on almost 500 LGV crashes are considered.

Three main issues are apparent. Firstly, there is an issue of crash compatibility between LGVs and passenger cars. The second issue involves restraint use among LGV occupants, since the in-depth data reveal that use is low compared with car occupants. The third issue is the implications of introducing a regulatory compliance crash test for LGVs.
\end{abstract}

Keywords: real-world accident data, light goods vehicles, vans, casualty rates, frontal impact, side impact, injuries, maximum abbreviated injury scale, injury risk, compatibility, aggressivity, restraint use, compliance crash test

\section{NOTATION}

$\begin{array}{ll}B & \text { aggressivity index } \\ R & \text { relative injury risk }\end{array}$

\section{INTRODUCTION}

According to British national statistics [1, 2], light goods vehicles (LGVs) [up to $3500 \mathrm{~kg}$ gross vehicle mass $(\mathrm{GVM})]$ are the second most common class of vehicle. During 1999 these vehicles made up 10.5 per cent of motor vehicles on the roads and this figure had increased slightly compared with 1989 figures (9.7 per cent).

The need for increased regulatory crash testing of LGVs is currently being debated. For example the EU Frontal Impact Directive contains a requirement that the scope of the Directive should be reviewed to examine the potential gains in occupant protection from including vehicles of the $\mathrm{N}_{1}$ category [3]. This raises two questions:

The MS was received on 21 July 2003 and was accepted after revision for publication on 24 December 2003.

* Corresponding author: Loughborough University, Vehicle Safety Research Centre (ESRI), Holywell Building, Holywell Way, Loughborough, Leicester LE11 3UZ, UK. (a) whether there is any advantage in subjecting such vehicles to regulatory crash tests;

(b) if so, which test conditions should be specified.

In order to answer these questions it is necessary to obtain an understanding of the current level of crashworthiness achieved by LGVs.

There have been a number of limited studies that have considered the nature and circumstances of LGV crashes. In a recent study in Germany [4], it was observed that, while such vehicles do not necessarily have a higher crash rate than other vehicles on the roads, crashes tend to occur in predominantly urban environments. This may have implications for more vulnerable road users who exist in greater numbers in urban areas with high traffic density. This issue was also noted by Lefler and Gabler [5]. Niewöhner et al. [4] observed that approximately 60 per cent of the crashes with passenger cars were frontal impacts while 20 per cent were struck-side crashes (i.e. side impacts where the occupant was on the side of the vehicle struck by the car), 6 per cent non-struck-side crashes (i.e. side impacts where the occupant was on the opposite side of the vehicle) and 16 per cent involved a rear impact. Belt use by drivers in such vehicles was relatively low, of the order of 20 per cent. 
Given the scarcity of crash data concerning such vehicles in Britain - and indeed in Europe generallythe main aim of this study is to make such data available so that informed choices concerning safety improvements can be made [6].

\section{METHODOLOGY}

The accident data presented in this paper come from two sources:

(a) the British national STATS19 database derived from police reports of injury accidents;

(b) an in-depth LGV database created for the Ford Motor Company at Loughborough University.

The STATS19 database contains records on several million injury accidents. In general there is a record for every accident in Great Britain reported to the police in which a road user was injured; however, the level of detail about the crashed vehicles and injury outcomes is relatively low.

The in-depth database has been compiled over 10 years, sampling primarily light trucks (up to $3500 \mathrm{~kg} \mathrm{GVM}$ ), car-derived vans and minibuses from three counties in the East Midlands. Accidents in which the target vehicle was towed away and an occupant (in any vehicle) was injured were included in the study. The database is essentially a random sample, although practical considerations dictate that repairs on a proportion of lightly damaged vehicles commence before an inspection can be conducted. Most vehicles were less than 6 years old at the time of the accident.

Two measures of vehicle compatibility are presented in section 3.4: an aggressivity index $B$ and a relative injury risk $R$ [7-10]. Relative to a cross-tabulation of the number of injured occupants in the subject and other vehicle as indicated in Table 1, these are defined by

$$
\begin{aligned}
B & =\frac{a+b}{a+b+c} \\
R & =\frac{a+c}{a+b}
\end{aligned}
$$

The aggressivity index $B$ is the ratio of occupants injured in the other vehicle to the total number of injured occupants. It ranges in value from 0 (low aggressivity)

Table 1 Tabulation of injured occupants

\begin{tabular}{lll}
\hline & \multicolumn{2}{c}{ Subject vehicle (LGV) } \\
\cline { 2 - 3 } Other & Injured & Not injured \\
\hline Injured & $a$ & $b$ \\
Not injured & $c$ & $d$ \\
\hline
\end{tabular}

to 1 (high aggressivity). The relative injury risk $R$ is the ratio of occupants injured in the subject vehicle to the number of occupants injured in the other vehicle. It ranges in value from 0 (low injury risk) to infinity (high injury risk). The number of occupants in non-injury accidents, denoted by $d$, is not used in the calculation of either measure.

\section{RESULTS}

\subsection{Overview}

The national fleets of LGVs vary widely between European countries, and between Europe and other regions of the world. Some salient features of the British fleet derived from the national STATS19 database are summarized in Table 2.

Car-derived vans are variants of passenger cars. The engine compartment and front axle of these vehicles are located forward of the passenger compartment. In the other categories of LGVs, the front seats are located more or less over the front axle. The heaviest and most common category of LGV in Britain usually has a longitudinal engine located slightly forward of the driver and front axle. This provides some opportunity for frontal crumple zones and energy-absorbing structures. This opportunity is far more limited for mid-size LGVs and micro-vans, which typically house the engine under the driver with the front end of the vehicle very close to the driver's feet.

The market share and kerb masses of such vehicles are also shown in Table 2, but these figures should be taken as indicative only. The national UK database does not fully list all makes and models, and there are potentially many variants or body types of each model, including the basic cab chassis, panel van, drop-side van, box van, refrigerated van, short or long wheelbase, single cab, dual cab, minivan, caravanette or ambulance.

Occupant casualties in Great Britain for the year 2000 are shown in Table 3 by vehicle category. LGVs have a GVM up to $3500 \mathrm{~kg}$; heavy goods vehicles (HGVs) have a GVM over $3500 \mathrm{~kg}$; public service vehicles (PSVs) include buses and coaches. LGVs account for 3-4 per cent of occupants in the three injury categories shown. Occupants are counted as fatalities if they die within 30 days of the accident. Serious injury implies loss of consciousness, fractures, severe lacerations or admission to hospital as an inpatient. Other injuries are classified as slight. A full description of these terms and definitions can be found in references [1] and [2].

Table 4 shows that drivers constitute 83 per cent of occupants killed in LGVs. This compares with 65 per cent of car occupants and only 7 per cent of PSV occupants. The proportion of drivers in the other injury categories (klled/serious and all injury) is also relatively high at 75 per cent compared with car occupants. 
Table 2 Characteristics of the British LGV fleet (GVM $<3500 \mathrm{~kg}), 1999$

Vehicle
Structure

Table 3 Vehicle occupant casualties (Great Britain, 2000)

\begin{tabular}{lrrrrrr}
\hline & Killed & \multicolumn{3}{c}{ Killed/serious } & All injury \\
\hline Car & 1665 & $92 \%$ & 19719 & $91 \%$ & 206799 & $91 \%$ \\
LGV & 66 & $4 \%$ & 813 & $4 \%$ & 7007 & $3 \%$ \\
HGV & 55 & $3 \%$ & 571 & $3 \%$ & 3597 & $2 \%$ \\
PSV & 15 & $1 \%$ & 578 & $3 \%$ & 10088 & $4 \%$ \\
Total & 1801 & $100 \%$ & 21681 & $100 \%$ & 227491 & $100 \%$ \\
\hline
\end{tabular}

Table 4 Percentages of drivers among vehicle occupant casualties (Great Britain, 2000)

\begin{tabular}{lcll}
\hline & Killed & Killed/serious & All injury \\
\hline Car & $65 \%$ & $64 \%$ & $65 \%$ \\
LGV & $83 \%$ & $75 \%$ & $75 \%$ \\
HGV & $76 \%$ & $84 \%$ & $84 \%$ \\
PSV & $7 \%$ & $9 \%$ & $10 \%$ \\
\hline
\end{tabular}

The in-depth accident sample, which provides detailed accident and injury information, contains predominantly full-size LGVs (81 per cent) as shown in Table 5, with a roughly even balance of mid-size and micro-vans among the remainder. Excluding the car-derived category, this is roughly comparable with the proportions in the national fleet as described in Table 3. No consideration

Table 5 LGV classes (in-depth sample)

\begin{tabular}{lrr}
\hline Full-size LGV & 402 & $81 \%$ \\
Mid-size LGV & 47 & $9 \%$ \\
Micro-van & 48 & $10 \%$ \\
Total & 497 & $100 \%$ \\
\hline
\end{tabular}

is given in this paper to the car-derived vehicles in the in-depth sample, in order to focus attention on the special characteristics of light truck and commercial vehicles.

The proportions of impact types for LGVs in the in-depth sample are shown in Fig. 1. Where a vehicle sustained multiple impacts, it is defined by the most severe impact. While it is acknowledged that multiple impacts can be considered as a separate category [11], it was felt useful in this initial analysis of LGV accident data to give a overview based on the most severe impact only. Finally, any case where a vehicle rolled one-quarter turn or more is classified as a rollover, irrespective of the severity of the impacts involved.

Seat belt use was primarily determined from examination of the vehicle after impact; occupants were also invited to state whether the restraint was used. Evidence for use was found for 47 per cent of drivers; a further 9 per cent claimed to be wearing the seat belt although no supporting physical evidence was identified. This

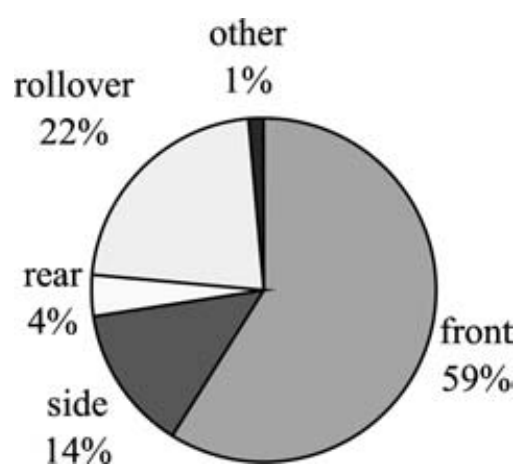

Fig. 1 Impact type, $N=497$ (in-depth sample)

Table 6 Seat belt use (in-depth sample)

\begin{tabular}{lrrrrrrrr}
\hline & Driver & & \multicolumn{2}{c}{ Front passenger } & Other passenger & \multicolumn{2}{c}{ Total } & \\
\hline Used & 233 & $47 \%$ & 4 & $11 \%$ & 71 & $18 \%$ & 308 & $33 \%$ \\
Claimed & 46 & $9 \%$ & 5 & $14 \%$ & 17 & $4 \%$ & 68 & $7 \%$ \\
Not used & 151 & $31 \%$ & 16 & $46 \%$ & 244 & $62 \%$ & 411 & $45 \%$ \\
Unknown & 62 & $13 \%$ & 10 & $29 \%$ & 61 & $16 \%$ & 133 & $14 \%$ \\
Total & 492 & $100 \%$ & 35 & $100 \%$ & 393 & $100 \%$ & 920 & $100 \%$ \\
\hline
\end{tabular}


often occurs, particularly in minor impacts and with certain types of restraint system. The rate of belt use among passengers is much lower than for drivers.

\subsection{Drivers in frontal impacts}

The results in this section relate to drivers in frontal impacts. Where an occupant died within 30 days of the accident, it is classified as a fatality irrespective of the severity of injury.

Survivors are categorised by their most severe injury on the abbreviated injury scale (AIS) system of coding [12]. This system classifies injury severity on a scale from 1 to 6 according to threat to life. AIS 1 typically represents bruises, abrasions, superficial lacerations and some minor skeletal fractures; AIS 2 includes brief loss of consciousness, many closed fractures and some lesser internal organ lesions; AIS 3-5 include the more severe skeletal fractures and many internal organ lesions that would normally be associated with hospitalization; AIS 6 includes devastating injuries currently considered to be untreatable. The maximum abbreviated injury scale (MAIS) score for an injured person is commonly used in analysis of accident data.

Noteworthy in Table 7 is the involvement of heavier road vehicles (LGVs, HGVs and PSVs) in accidents where LGV drivers were killed (six of 13 cases) or injured to MAIS $2+$ level (46 of 99 cases). This is particularly significant since these heavier vehicles constitute a small proportion of the total vehicle fleet.

Table 8 indicates where direct contact with the object struck occurred on the front surface of the vehicle. Overall, direct contact was contained within the right one-third of the front surface in 16 per cent of cases, involved the right two-thirds of the front surface in 20 per cent of cases and involved all three thirds of the front surface in 37 per cent of cases. This pattern was fairly consistent within the separate levels of injury outcome.

The severity of impacts in the in-depth sample, where known, is shown in Fig. 2 by the equivalent test speed (ETS). The ETS is based on damage to the vehicle involved. Over 75 per cent of non-fatal injury cases occurred below $50 \mathrm{~km} / \mathrm{h}$. The number of fatalities in the sample with known ETS is too small to form a smooth distribution but can be seen to include several very severe impacts.

The rate of seat belt use among drivers in frontal impacts is shown in Table 9. Overall belt use was confirmed or claimed in 57 per cent of cases, with a markedly lower rate among fatalities.

Table 10 shows the distribution of MAIS per body region for 312 drivers in frontal impacts; for example, 51 per cent of drivers had no head injury, the most severe head injury for 32 per cent of drivers was AIS 1, the most severe head injury for 10 per cent of drivers was

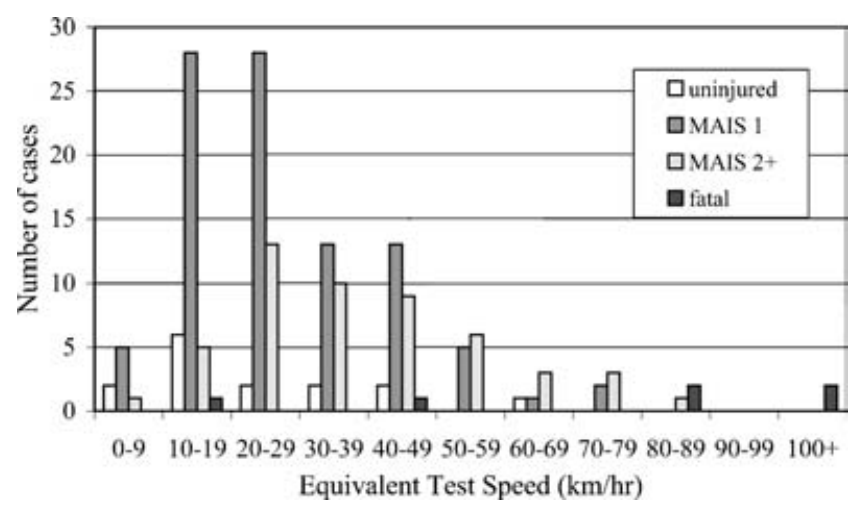

Fig. 2 Impact severity for frontal impacts, $N=170$ (in-depth sample)

Table 7 Object struck in frontal impacts (in-depth sample)

\begin{tabular}{lccccrr}
\hline & Fatal & MAIS 2 & MAIS 1 & MAIS 0 & Total* \\
\hline Car & 2 & 37 & 83 & 19 & 143 & $46 \%$ \\
LGV, HGV, PSV & 6 & 46 & 40 & 1 & 94 & $30 \%$ \\
Fixed object (narrow) & 1 & 5 & 25 & 4 & 35 & $11 \%$ \\
Fixed object (wide) & 1 & 5 & 10 & 1 & 17 & $5 \%$ \\
Other/unknown & 3 & 6 & 9 & 5 & 23 & $7 \%$ \\
Total & 13 & 99 & 167 & 30 & 312 & $100 \%$ \\
\hline
\end{tabular}

*Includes three cases with unspecified injury outcome.

Table 8 Offset in frontal impacts (in-depth sample)

\begin{tabular}{lclcrrr}
\hline & Fatal & MAIS 2 & MAIS 1 & MAIS 0 & \multicolumn{2}{c}{ Total } \\
\hline Right side (one-third) & 1 & 15 & 29 & 4 & 49 & $16 \%$ \\
Right side (two-thirds) & 5 & 22 & 28 & 6 & 61 & $20 \%$ \\
Distributed & 6 & 42 & 53 & 11 & 115 & $37 \%$ \\
Other & 1 & 20 & 57 & 9 & 87 & $28 \%$ \\
Total & 13 & 99 & 167 & 30 & 312 & $100 \%$ \\
\hline
\end{tabular}

*Includes three cases with unspecified injury outcome. 
Table 9 Seat belt use for drivers in frontal impacts (in-depth sample)

\begin{tabular}{lccccrr}
\hline & Fatal & MAIS 2 + & MAIS 1 & MAIS 0 & Total* & \\
\hline Used & 3 & 45 & 83 & 11 & 143 & $46 \%$ \\
Use claimed & - & 9 & 20 & 4 & 33 & $11 \%$ \\
Not used & 10 & 40 & 37 & 8 & 97 & $31 \%$ \\
Unknown & - & 5 & 25 & 7 & 37 & $12 \%$ \\
Total & 13 & 99 & 165 & 30 & 310 & $100 \%$ \\
\hline
\end{tabular}

*Includes three cases with unspecified injury outcome

Table 10 MAIS per body region for drivers in frontal impacts (in-depth sample)

\begin{tabular}{|c|c|c|c|c|c|c|c|}
\hline & AIS 0 & AIS 1 & AIS 2 & AIS $3+$ & Unknown & Total & \\
\hline Head & $51 \%$ & $32 \%$ & $10 \%$ & $4 \%$ & $3 \%$ & $100 \%$ & 312 \\
\hline Spine & $68 \%$ & $28 \%$ & $1 \%$ & $0 \%$ & $4 \%$ & $100 \%$ & 312 \\
\hline Chest & $68 \%$ & $19 \%$ & $4 \%$ & $5 \%$ & $3 \%$ & $100 \%$ & 312 \\
\hline Abdomen & $90 \%$ & $5 \%$ & $1 \%$ & $1 \%$ & $3 \%$ & $100 \%$ & 312 \\
\hline Lower limbs & $51 \%$ & $29 \%$ & $6 \%$ & $10 \%$ & $4 \%$ & $100 \%$ & 312 \\
\hline Upper limbs & $57 \%$ & $32 \%$ & $5 \%$ & $2 \%$ & $3 \%$ & $100 \%$ & 312 \\
\hline MAIS & $6 \%$ & $49 \%$ & $19 \%$ & $15 \%$ & $10 \%$ & $100 \%$ & 312 \\
\hline
\end{tabular}

AIS 2 and so on. In this table facial injuries are included in 'head', neck injuries in 'spine', and pelvic injuries in 'lower limbs'. The most frequent locations of AIS $2+$ injuries are the lower limbs (16 per cent), head (14 per cent) and chest ( 9 per cent).

\subsection{Drivers and front passengers in struck-side impacts}

The results presented in this section relate to drivers and (outboard) front passengers in struck-side impacts. These are impacts to the right side of the vehicle for an occupant sitting in the right-hand front seat, or an impact to the left side of the vehicle for an occupant sitting in the left-hand front seat.

LGVs in the in-depth sample involved in side impacts were mostly struck by another road vehicle, 64 per cent by passenger cars and 27 per cent by larger vehicles (LGVs, HGVs and PSVs), as shown in Table 11.

Table 12 indicates that the striking object made direct contact with some part of the passenger compartment of the subject LGV in 73 per cent of cases.

Figure 3 indicates that most side impacts were under $30 \mathrm{~km} / \mathrm{h}$ as measured by the ETS. The sample size is small and does not include any cases of fatal injury where the ETS could be calculated.

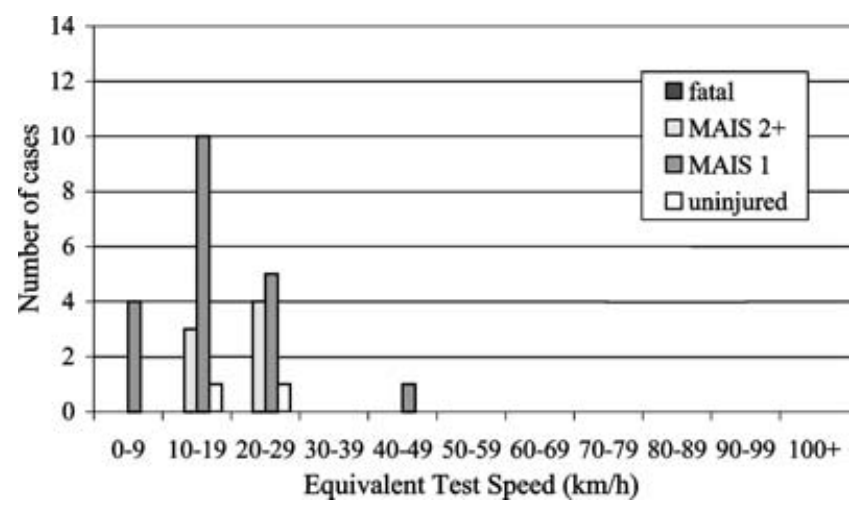

Fig. 3 Impact severity for side impacts, $N=29$ (in-depth sample)

Use of the seat belt was confirmed or claimed in 60 per cent of side impact cases, as shown in Table 13.

Table 14 shows the distribution of MAIS per body region for 45 front seat occupants in side impacts: for example, 69 per cent of the occupants had no lower limb injury, the most severe lower limb injury for 18 per cent was AIS 1, the most severe lower limb injury for 4 per cent was AIS 2 and so on. Facial injuries are included in 'head', neck injuries in 'spine', and pelvic injuries in

Table 11 Object struck in side impacts (in-depth sample)

\begin{tabular}{llllllr}
\hline & Fatal & MAIS 2 + & MAIS 1 & MAIS 0 & \multicolumn{2}{c}{ Total* } \\
\hline Car & - & 7 & 19 & 2 & 29 & $64 \%$ \\
LGV, HGV, PSV & 2 & 2 & 5 & 3 & 12 & $27 \%$ \\
Fixed object (narrow) & 1 & 1 & 1 & - & 3 & $7 \%$ \\
Fixed object (wide) & - & - & - & - & 0 & - \\
Other/unknown & - & - & 1 & - & 1 & $2 \%$ \\
Total & 3 & 10 & 26 & 5 & 45 & $100 \%$ \\
\hline
\end{tabular}

* Includes one case with unspecified injury outcome. 
Table 12 Offset in side impacts (in-depth sample)

\begin{tabular}{llllllr}
\hline Fatal & MAIS 2 + & MAIS 1 & MAIS 0 & Total* & \\
\hline Passenger compartment & 2 & 10 & 17 & 4 & 33 & $73 \%$ \\
Other & 1 & - & 9 & 1 & 12 & $27 \%$ \\
Total & 3 & 10 & 26 & 5 & 45 & $100 \%$ \\
\hline
\end{tabular}

*Includes one case with unspecified injury outcome.

Table 13 Seat belt use for front occupants in side impacts (in-depth sample)

\begin{tabular}{llcclrr}
\hline & Fatal & MAIS 2 + & MAIS 1 & MAIS 0 & \multicolumn{2}{c}{ Total* } \\
\hline Used & 2 & 7 & 10 & 2 & 22 & $49 \%$ \\
Use claimed & - & - & 4 & 1 & 5 & $11 \%$ \\
Not used & 1 & 2 & 9 & 1 & 13 & $29 \%$ \\
Unknown & - & 1 & 3 & 1 & 5 & $11 \%$ \\
Total & 3 & 10 & 26 & 5 & 45 & $100 \%$ \\
\hline
\end{tabular}

*Includes one case with unspecified injury outcome.

Table 14 MAIS per body region for front occupants in side impacts (in-depth sample)

\begin{tabular}{|c|c|c|c|c|c|c|c|}
\hline & AIS 0 & AIS 1 & AIS 2 & AIS $3+$ & Unknown & Total & \\
\hline Head & $40 \%$ & $40 \%$ & $9 \%$ & $7 \%$ & $4 \%$ & $100 \%$ & 45 \\
\hline Spine & $62 \%$ & $31 \%$ & $2 \%$ & $0 \%$ & $4 \%$ & $100 \%$ & 45 \\
\hline Chest & $62 \%$ & $27 \%$ & $2 \%$ & $4 \%$ & $4 \%$ & $100 \%$ & 45 \\
\hline Abdomen & $91 \%$ & $0 \%$ & $0 \%$ & $4 \%$ & $4 \%$ & $100 \%$ & 45 \\
\hline Lower limbs & $69 \%$ & $18 \%$ & $4 \%$ & $4 \%$ & $4 \%$ & $100 \%$ & 45 \\
\hline Upper limbs & $47 \%$ & $36 \%$ & $11 \%$ & $2 \%$ & $4 \%$ & $100 \%$ & 45 \\
\hline MAIS & $7 \%$ & $53 \%$ & $22 \%$ & $7 \%$ & $11 \%$ & $100 \%$ & 45 \\
\hline
\end{tabular}

'lower limbs'. The most frequent locations of AIS $2+$ injuries are the head (16 per cent), upper limbs (13 per cent) and lower limbs (8 per cent).

\subsection{Compatibility}

A breakdown of driver injury outcomes in collisions between cars and LGVs are shown in Table 15. This is based on national British data from 1994 to 1998.

There are 36347 cases recorded of an LGV colliding with a car. In around half of these (18573), the car driver was slightly injured and the LGV driver was uninjured, according to police records. The number of cases in which both drivers were uninjured (shown

Table 15 Driver injury outcome in LGV-to-car accidents (GB 1994-98)

\begin{tabular}{lccccc}
\hline & \multicolumn{5}{c}{ LGV } \\
\cline { 2 - 5 } Car & Uninjured & Slight & Serious & Fatal & \multirow{2}{*}{ Total } \\
\hline Uninjured & {$[5250]$} & 5748 & 423 & 8 & {$[11429]$} \\
Slight & 18573 & 3263 & 273 & 7 & 22116 \\
Serious & 1645 & 605 & 320 & 16 & 2586 \\
Fatal & 63 & 92 & 55 & 6 & 216 \\
Total & {$[25531]$} & 9708 & 1071 & 37 & {$[36347]$} \\
\hline
\end{tabular}

in square brackets) understates the actual number of cases since police records are not routinely collected for non-injury accidents.

The aggressivity index and relative injury risk index are used here to quantify the compatibility of LGVs in collisions with passenger cars. This number of accidents in which neither driver was injured does not affect the calculation of these indices. Table 16 is derived directly from Table 15. Using the definitions given in section 2 the aggressivity index and relative injury risk are calculated for LGVs and cars for three groups of drivers: killed; killed or seriously injured; all injury levels.

Table 16 Drivers killed, killed or seriously injured, and injured in LGV-to-car accidents (GB 1994-98)

\begin{tabular}{llcr}
\hline & & \multicolumn{2}{c}{ LGV } \\
\cline { 3 - 4 } Driver & Car & No & Yes \\
\hline \multirow{2}{*}{ Killed } & No & {$[36100]$} & 31 \\
& Yes & 210 & 6 \\
Killed/serious & No & {$[32834]$} & 711 \\
& Yes & 2405 & 397 \\
All injury & No & {$[5750]$} & 6179 \\
& Yes & 20281 & 4637 \\
\hline
\end{tabular}


For drivers killed (Table 16, first two rows),

$$
\begin{array}{lll}
\text { Aggressivity index: } & B_{\mathrm{LGV}}=0.87 & B_{\mathrm{car}}=0.15 \\
\text { Relative injury risk: } & R_{\mathrm{LGV}}=0.17 & R_{\mathrm{car}}=5.84
\end{array}
$$

For drivers killed or seriously injured (Table 16, middle two rows),

$$
\begin{array}{lll}
\text { Aggressivity index: } & B_{\mathrm{LGV}}=0.80 & B_{\mathrm{car}}=0.32 \\
\text { Relative injury risk: } & R_{\mathrm{LGV}}=0.40 & R_{\mathrm{car}}=2.53
\end{array}
$$

For all injured drivers (Table 16, last two rows),

$$
\begin{array}{lll}
\text { Aggressivity index: } & B_{\mathrm{LGV}}=0.80 & B_{\mathrm{car}}=0.35 \\
\text { Relative injury risk: } & R_{\mathrm{LGV}}=0.43 & R_{\mathrm{car}}=2.30
\end{array}
$$

As can be seen from the above results the risk of injury at all levels of severity is greater in cars than in vans. This raises a number of compatibility issues.

\section{DISCUSSION}

This study has highlighted a number of interesting points and three main issues warrant further discussion.

Firstly the issue of compatibility needs to be considered. Using both the aggressivity index and the relative injury risk index, it can be seen that in car-toLGV crashes, it is the drivers of cars who are at greatest risk of injury at every level of severity. In many respects this finding is in accordance with intuitive expectations since LGVs tend to have greater size and mass. In addition, for reasons connected with their construction and intended use (e.g. the need for ground clearance and loading height requirements), LGVs usually have their stiff structures at a greater height than those of passenger cars. This misalignment of stiff structures can result in the large vehicle overriding the smaller vehicle. This in turn has the effect of penalizing the occupants of the smaller collision partner, since there is an inherent risk of greater intrusion in the smaller vehicles which are already at a mass disadvantage. While compatibility is a broad issue that is difficult to confine to single parameters such as mass or stiffness, the available literature appears to suggest that geometrical incompatibility is a dominant feature in many cases [13].

A second consideration is that of restraint use among occupants of LGVs. The evidence in favour of restraint use in vehicles is overwhelming. However, in this study, approximately one-third of drivers and almost half of passengers were found not to have been wearing the seat belt at the time of the crash. In the fatal crashes that were investigated in this study, ten of 13 drivers ( 77 per cent) were not wearing seat belts. It would seem appropriate therefore to explore strategies for increasing seatbelt-wearing rates among LGV occupants. Possibilities include the use of in-vehicle seat belt reminder systems, higher profile awareness and education programmes, stricter policing and enforcement actions, and a review of the categories of occupants who are currently exempted from mandatory wearing of seat belts. Alternatively, consideration could be given to enhanced protection of unbelted occupants. This option would require careful consideration and the US experience of passive restraint systems for unbelted occupants would need to be taken into account.

The third issue concerns the need for and the nature of regulatory compliance crash-testing for LGVs. It is not immediately obvious from this study that there is a need to improve the occupant protection in such vehicles. There is, however, a strong case for exploring ways of improving crash compatibility in impacts between LGVs and cars. Such impacts are common and currently carry a high injury risk for the car occupants. There is a serious possibility that the introduction of regulatory crash tests could increase the level of incompatibility, as the actions required to offer 'improved' performance in the crash tests may involve stiffening and reinforcement of the front end structure. As a result, it is suggested that regulatory crash-testing option may have an overall negative effect on road safety. However, if the conditions chosen for any crash tests were aimed at encouraging compatibility (e.g. by improved geometric compatibility, load-spreading, etc.) without resulting in increased local stiffness, the overall effect could be beneficial. When considering test conditions, the data here do not appear to support a particular case for either an offset or fully distributed frontal crash-test requirement since both crash types occur with roughly equal frequencies (36 per cent and 37 per cent) and with similar injury outcomes.

There are clearly many other issues related to LGV safety that have not been considered in this study. For example, the performance of cargo barriers and load interaction within the vehicle for which a follow-up study is planned. A future study is also planned which will address the issue of injury types and trends in crashes involving LGVs.

\section{CONCLUSIONS AND RECOMMENDATIONS}

1. LGV crashes comprised around 3 per cent of all British vehicle occupant casualties and 4 per cent of fatally injured occupant casualties during 2000. A large majority of serious and fatally injured LGV occupants in such crashes are drivers.

2. The in-depth study of LGVs reveals that 59 per cent involve a frontal impact while 22 per cent involve rollover crashes.

3. Seat belt use among occupants of LGVs involved in crashes is relatively low, being approximately 50 per cent for drivers and 30 per cent for passengers. 
4. 46 per cent of crashes involve a passenger car as the collision partner and 30 per cent involve a second LGV, HGV or PSV. There is a roughly equal split between offset frontal (36 per cent) and fully distributed frontal ( 37 per cent) crashes.

5. The lower limbs, head and chest are highlighted as locations of serious injury for drivers in frontal impacts; for drivers and front seat passengers in side impacts the corresponding results are head, upper limbs and lower limbs.

6. Aggressivity and a relative injury risk indices indicate that occupants of cars involved in crashes with LGVs have a much higher risk of injury and fatality than the occupants of the LGVs.

7. The introduction of regulatory compliance crash testing for LGVs needs to be carefully considered since it may have significant implications for other road users.

\section{ACKNOWLEDGEMENTS}

The Ford Motor Company Limited provided funding for this study. Grateful thanks are extended to everyone involved with the data collection.

\section{REFERENCES}

1 DTLR Road Accidents Great Britain - The Casualty Report, 2000 (Department for Transport, Local Government and the Regions, London).

2 DETR Transport Statistics Great Britain, 2000 (Department of Transport, Environment and the Regions, London).

3 Directive 96/79/EC of the European Parliament and of the Council. Official J. Eur. Communities, January 1997.
4 Niewöhner, W., Berg, F. A. and Froncz, M. Accidents with vans and box-type trucks (transporters); results from official statistics and real-life crash analyses. In Proceedings of Enhanced Safety in Vehicles Conference (ESV 2001), Amsterdam, The Netherlands, 2001, pp. 1-11.

5 Lefler, D. and Gabler, H. C. The emerging threat of light truck impacts with pedestrians. In Proceedings of Enhanced Safety in Vehicles Conference (ESV 2001), Amsterdam, The Netherlands, 2001, pp. 1-6.

6 Berg, A., Rücker, P., Groer, M., Niewöhner, W., Sferco, R., Fay, P. and Schriever, T. Safety of light commercial vehicles in the light of the results of accident analysis and testing. In Proceedings of Enhanced Safety in Vehicles Conference (ESV 2003), Nagoya, Japan, 2003, pp. 1-15.

7 Broughton, J. The theoretical basis for comparing the accident record of car models. Project Report 70, TRL, Crowthorne, Berkshire, UK, 1994.

8 Krafft, M., Kullgren, A., Lie, A., Nygren, A. and Tingvall, C. Car model safety rating based on real life accidents. In Proceedings of the International IRCOBI Conference on the Biomechanics of Impact, Verona, Italy, 1991, pp. 25-40.

9 Von Koch, M., Kullgren, A., Lie, A. and Tingvall, C. Car model safety rating using the paired comparison method. In Proceedings of Enhanced Safety in Vehicles Conference 1991, Paris, France, pp. 78-82.

10 Les, M., Fildes, B., Newstead, S. and Seyer, K. Vehicle compatibility analysis using casualty data. IMechE Conference Transactions on Vehicle Safety, London, June 2000, pp. 29-44.

11 Fay, P. A., Sferco, R. and Frampton, R. Multiple impact crashes - consequences for occupant protection measures. In Proceedings of IRCOBI 2001, Isle of Man, UK, pp. 271-282.

12 AAAM The Abbreviated Injury Scale: 1990 Revision, 1990 (Association for the Advancement of Automotive Medicine, Des Plaines, Illinois).

13 Hobbs, C. A., Williams, D. A. and Coleman, D. J. Compatibility of cars in frontal and side impact. In Proceedings of Enhanced Safety in Vehicles Conference (ESV 1996), Melbourne, Australia, 1996, pp. 617-624. 